\title{
An Analysis on the Antenatal Care Service Factors Affecting Pregnant Women in Bangladesh: A Special Review on Private Hospitals
}

\author{
Shapla Akter ${ }^{1}$, Tarazul Islam ${ }^{2}$, Al Mamun Sarker ${ }^{3}$, Md. Shohel Rana ${ }^{4 *}$, Ashrafi Alim Roki ${ }^{5}$ \\ ${ }^{1}$ Jahanara Nursing College, Sirajganj, Bangladesh \\ ${ }^{2}$ Sakhawat H. Memorial Nursing College, Sirajganj, Bangladesh \\ ${ }^{3}$ Department of Social Work, Bangamata Sheikh Fojilatunnesa Mujib Science \& Technology University, \\ Jamalpur, Bangladesh \\ ${ }^{4}$ Department of Business Administration, European University of Bangladesh, Dhaka, Bangladesh \\ ${ }^{5}$ TMSS Medical College and Rafatullah Community Hospital, Bagura, Bangladesh
}

\begin{abstract}
The rate of maternal mortality of Bangladesh is increasing day by day. Among many reasons early marriage, unplanned impregnation or lack of antenatal care are the major causes of those maternal deaths. Antenatal care is significantly effective for the mother and their newborns during pregnancy period especially from severe bleeding, high blood pressures, infections or complications during delivery. Several researches have conducted in various countries about the antenatal care service factors affecting pregnant women during pregnancy period but have not been organized information collectively. Hence, further research need to accomplish a literature review for finding organized information about the antenatal care service factors affecting pregnant women in Bangladesh. This is a descriptive analysis based on the information extracted from different literature review, primary and secondary data sources by using a specific methodology. The study found that 60.87 percent pregnant women have adequate information about the ANC services and 39.13 percent have partial knowledge about the ANC services. The major outcomes of this special review study might help the respective authorities and interested groups to make plan and improvement existing approaches for application of ANC factors affecting pregnant women in Bangladesh.
\end{abstract}

Keywords: Antenatal Care Service (ANC), Pregnant women, Private hospital, Bangladesh.

\section{Introduction}

Antenatal Care (ANC) is the care a pregnant woman requires in order to ensure a healthy pregnancy and safe childbirth. A pregnant woman is supposed to have regular check-ups with a midwife or a doctor who has a specialization in pregnancy and birth. These check-ups are called antenatal visits. The ANC visits persuade pregnant mothers to opt for skilled attendance at birth and encourage them to have some healthy behaviors such as early breastfeeding, early postnatal care and planning for optimal pregnancy spacing. ANC include four important visits to achieve the full life saving for women and babies which often called focused antenatal care (Yohannes, et al. 2013). Among the four recommended visits, the first one is advised at eight to twelve weeks, the second one at twenty-four to twenty-six weeks, the third one at thirty-two weeks and the fourth one at thirty-six to thirty-eight weeks of the pregnancy (Begum, N. et al. 2014). The practice of having checkups during pregnancy is very low in developing countries compared to developed countries like Bangladesh. In developed countries, majority of pregnant mothers have access to ANC but in Bangladesh the percentage is still very low compared to developed countries (Shahjahan, et al. 2012). Studies conducted on antenatal care in Bangladesh reveals the frequency of antenatal care visits is lower for women belonging to poor families. Pregnancy related complications kills' large percentage of pregnant mothers in Bangladesh (Ali, S.A. et al. 2018). Thus, proper care during pregnancy and delivery is extremely necessary for Bangladesh. Since majority of the poor people are uneducated, they do not have knowledge of safe pregnancy and childbirth. They consider pregnancy as an everyday occurrence so the husbands of the pregnant women do not make any effort to access the next clinic for antenatal care. Academic qualifications of the mother and father also play a pivotal role in the number of ANC visits. Studies revealed that mothers who are educated have more access to antenatal care than the uneducated and early married pregnant women in Bangladesh (Pervin, J. et al. 2012). It also revealed that educated men are much more willing to take their pregnant wives for treatment compared to uneducated men. Some studies showed that rural mothers have lower access to safe childbirth. Since in villages there is scarce of good hospitals, women often have no proper treatment during pregnancy complications (Ali, N. et al. 2018). Though a number 
of studies have been conducted on antenatal care in Bangladesh, only a few of them involve statistical estimation of the relationship between number of antenatal visits and different socio-economic factors. The main aim of this study is to identify the factors affecting the inadequate utilization of antenatal care among pregnant women. The findings can be helpful for organizations that are working for improving maternal health, neonatal heath and ensure a safe pregnancy and childbirth. The recommendation of this study may help to formulate new strategies to develop the factors affecting pregnant women and a safe child birth.

\section{Methodology}

This is a descriptive study in nature used both qualitative and quantitative methods conducted at TMSS Medical College (TMC) and Rafatullah Community Hospital ( $\mathrm{RCH})$ in Bogura district from July 2019 to December 2019. Data has been collected through purposive sampling method by developed a structured questionnaire. Both inclusion and exclusion criteria have followed for collecting data with a sample size of 115 respondents. Data collected from the women visiting at antenatal care unit at least 1 to 5 times and who are too weak to visit. Various statistical techniques have been applied to analyze on the basis of classified information and presented in compatible tables and charts.

\section{Objectives}

- To analyze the ANC service factors affecting pregnant women in Bangladesh.

- To identify the socio-demographic features of the pregnant women.

- To assess the knowledge of the respondents about is ANC.

- To measure the superiority of ANC facilities received by the respondents and give recommendations with a view to improve the present condition of ANC services in private medical hospitals in Bangladesh.

\section{Review of the Literature}

With the touch of globalization everything in the world has changed dramatically but the healthiness of females and families especially pregnant women and new birth babies remains a fragmentary outline and still faces a worldwide challenge. Exertions and investments are desirable to endure the situation and hasten improvement if countries and the global community are to prevent maternal and child disease and reach the related Sustainable Development Goals(SDG's) (Moller, A.B et al. 2017). Antenatal care can be defined as the tedious care of pregnant women providing from the time of conception to commencement of newborns. Antenatal care is an opportunity to provide care for prevention and management of existing and potential causes of maternal and newborn mortality and morbidity (Basha W.G. (2019). In development countries major portion of pregnant women have an easy access to take antenatal care service with skilled personnel at least six times visit. On the other hand, developing countries scenario is different; the women have less knowledge about the antenatal care service even who are knowledgeable visits three or four times with a doctor, nurse or midwife (UNICEF, 2015). Antenatal care service is very much indispensable for defending the health of women and their newborns. Skilled doctors, nurses and midwives can help the pregnant women come from both urban and rural areas about the healthy behaviors during pregnancy, better understand about warning signs during pregnancy and giving birth, and receive social, emotional and psychological support at this critical time in their lives through this form of preventive health care. By this program, pregnant women can also gather knowledge about the micronutrient supplementation, a safe birth of child, treatment for hypertension to avoid eclampsia, as well as vaccination against tetanus. Antenatal care can also provide information about HIV testing that prevents mother-to-child transmission of HIV, about malaria endemic and other information helps to prevent or debilitating such deadly diseases (UNICEF, 2021). Early entry to antenatal care service is very much significant for early detection and management of antagonistic pregnancy-related outcomes because of the level of maternal mortality is unacceptably high world widely. (Adekanle, D.A, et al. 2008).

The maternal death ratio is the amount of women who die during pregnancy and giving birth, per 100,000 live births. Everyday approximately 810 women died from preventable causes related to pregnancy and childbirth in the year of 2017. Studies found that from 2000 to 2017 the maternal mortality ratio decreased by 38 percent world widely where the ratio of maternal deaths is 94 percent in low and lower middle-income countries in the world. The World Health Organization (WHO) also recommends that pregnant women in developing countries should seek ANC within the first 4 months of pregnancy. Approximately, 295000 pregnant women died during and following pregnancy and childbirth in the year of 2017. The majority percentage of those deaths (94 percent) happened in low-resource surroundings and they did not get a proper ANC services. Globally 30 percent of women between the age group of 15-40 years do not have ANC, 46 percent of those who did not have ANC are in South Asia while 34 percent are in subSaharan Africa. This low use of services leads to death and disability due to untreated hypertensive disorders or due to malor sub-nutrition like iron deficiency anemia (WHO, 2019). Studies also found that major causes of maternal death are abortion, embolism, haemorrhage, hypertension and sepsis etc. (Say L. et al. 2014). A study also done in Bangladesh showed that the probability for use of ANC in women in the highest wealth index group is higher despite their difference in place of residence and educational level, women were found to have a higher level of use of ANC. This depicts that household wealth is a very strong determinant of health service utilization (Bilenko, 2007). Studies also reveal that nearly 23.4 percent women received these recommended four or more antenatal visits with a doctor, nurse or midwife in Bangladesh. Although the number of women who received antenatal care has been increasing gradually, the current trend will not be sufficient to reach the target set for 2030 called Sustainable Development Goals (SDGs) (Chowdhury S. et al. 2011). Further research found that in 2017, maternal mortality ratio for Bangladesh was 
173 deaths per 100,000 live births. The maternal mortality ratio of Bangladesh is deteriorating from 395 deaths per 100,000 live births in 2003 to 173 deaths per 100,000 live births in 2017. On the other hand, neonatal mortality rate is 17.1 deaths per 1000 live births in 2018 , under five mortality rate is 30.2 deaths per 1000 live births and total fertility rate is 2.0 live births per women in 2020 (WHO, 2020). However, in the present study authors try to analysis the antenatal care service factors affecting pregnant women and focus on the strategy development related to antenatal care service factors in private medical hospitals of Bangladesh.

\section{Data Analysis and Discussion}

The review study is conceptualized from the healthcare utilization model developed by Andersen designed to signify the components which help to enrich the health services effectively. According to Andersen there are three dynamics of a sound health care services- predisposing factors, enabling factors and need factors (Andersen, 1995). In this review study the results and discussion are adopted from the model.

The descriptive study was carried out among pregnant women attending the antenatal care unit of TMC and RCH. A whole of $n=115$ respondents were comprised in this study. The results of the study are shown following:

\section{A. Demographic Aspects as Predisposing Factors}

Demographic factors generally consider as the common factor of respondents. Demographic factors included age, academic qualifications, occupations, family income, standard of living and number of family members etc.

\section{1) Respondents Age}

Studies found a mixed result about the correlation between the respondent's age and application of ANC service programs. Studies found that the women from the age group 22 to 15 have been recognized as a predisposing factor for utilization of ANC services (Amponsah E.N. 2013). From this study, figure 1 shows that out of 115 respondents 43.48 percent women are from age group (22-25), 40 percent are from (18-21 Years), 11.31 percent are from (26-29years) and rest (5.21 percent) are from age group (above 30 years).

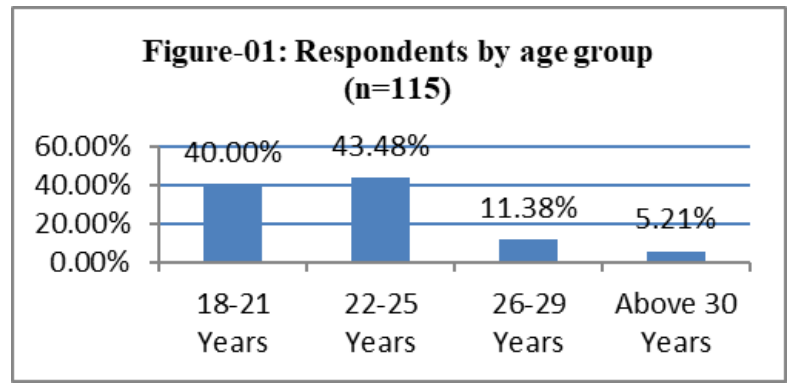

Fig. 1. Respondents by age group $(\mathrm{n}=115)$

\section{2) Respondents Academic Qualifications}

Studies found that educated women are more aware about their health care service than the uneducated (Efendi, F. et al. 2016). Proper education helps women to expose them to get health education messages, health campaigns, health news and opportunities and enabling them to identify danger signs and complexities during pregnancy period (Zhao, QZJH et al. 2012). From this study, figure 2 shows that out of 115 respondents 13.03 percent women are illiterate, 13.92 percent have primary education, 12.17 percent have HSC, 4.35 percent have honors or above level education. In the figure 2, it shows that bulk of the respondents (56.52 percent) have SSC level of education. It found that the levels of education of women need to expand that they can get more education and ensure themselves a standard ANC services.

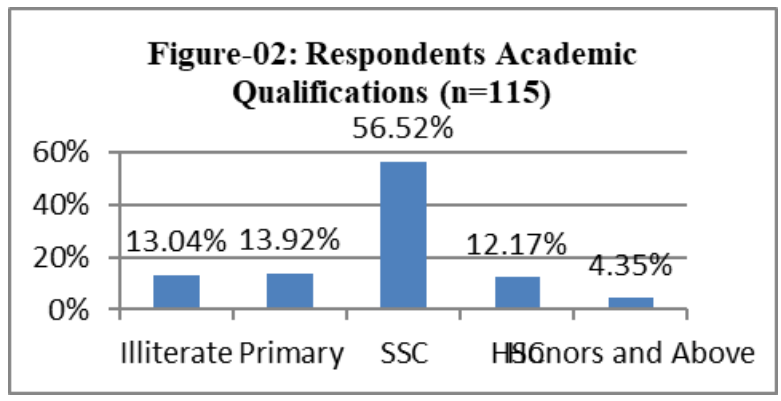

Fig. 2. Respondents Academic Qualifications ( $\mathrm{n}=115)$

\section{3) Respondents Occupations}

Occupation is a social status which makes women financially solvent. Without any income source women passes financial hardship in their life. A woman with a recognized occupation can gather knowledge about health care services and can visit ANC service centers during their pregnancy period. From this study, figure 3 shows that out of 115 respondents 79.13 percent women are housewife, 3.48 percent women are involved in small and cottage industries, 7.28 percent are service holder and rest 10.11 percent are involved in other activities to manage their livings. Data shows that 79.13 percent women are housewife which is the main obstacle for taking ANC services. Because, an empowered women have more access in all sectors than an unpowered women. Occupation mainly makes person empowered financially and socially.

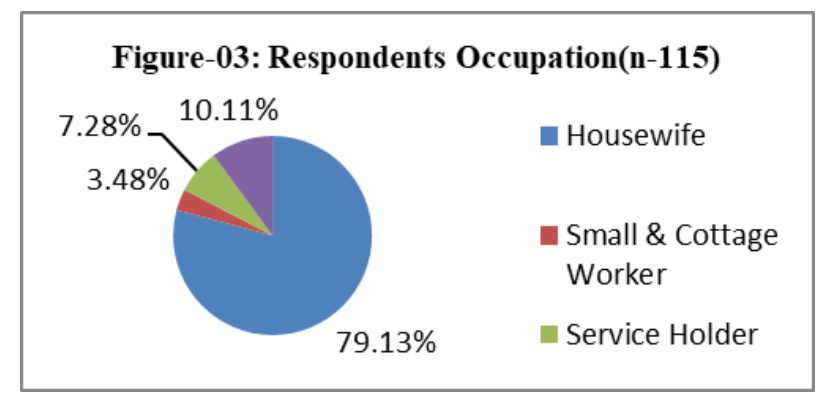

Fig. 3. Respondents Occupation ( $\mathrm{n}=115)$

\section{4) Partners Academic Qualifications}

Husband's educational qualification and knowledge is another factor affecting antenatal services. An educated husband is always careful to his better half about their health related issues. Data of this study (Table 1) shows that 35.66 percent husbands have primary education, 30.43 percent husbands have SSC education, 30.43 percent husbands have HSC education and lest percent (3.48) have honors or above 
education. The level of husbands education need to enhance that they become more aware about ANC services.

Table 1

Husbands Educational Qualifications, n=115

\begin{tabular}{|l|l|l|}
\hline Husbands Educational Qualification & Frequency & Percentage \\
\hline Primary & 41 & $35.66 \%$ \\
\hline S.S.C & 35 & $30.43 \%$ \\
\hline H.S.C & 35 & $30.43 \%$ \\
\hline Honors or above & 04 & $3.48 \%$ \\
\hline Total & 115 & $100 \%$ \\
\hline
\end{tabular}

\section{5) Level of Family Income}

Financial hardship is another considerable obstacle to ANC services for women. Utmost of the studies discovered a positive correlation between the level of economic standing and the application of ANC services (Efendi, F. et al. 2016). From this study (Table 2) it shows that, 41.74 percent family's income level is between TK. 5,000 to TK. 9,000, 45.22 percent family's income level is between TK. 10,000 to TK. 15,000 and lest 13.04 percent family's income level is between TK. 16,000 to TK. 20,000.

Table 2

Level of Family Income, $n=115$

\begin{tabular}{|c|c|c|}
\hline Family Income & Frequency & Percentage \\
\hline Taka 5000-9000 & 48 & $41.74 \%$ \\
\hline Tk10000- 15000 & 52 & $45.22 \%$ \\
\hline Taka 16000-20000 & 15 & $13.04 \%$ \\
\hline Total & 115 & $100 \%$ \\
\hline
\end{tabular}

\section{6) Number of Children's}

Number of existing children is another considerable factor for women. Pregnancy complexities occur suddenly but most of the mothers think if they didn't face any complexity in delivering their first or second or previous kids; they will not face complexity in present period of pregnancy. Data shows that (Table 3), 34.78 percent have no children yet, 30.43 percent have one child, 21.74 percent have 2 children, 6.96 percent have 3 children and lest 6.09 percent have four or above children.

Table 3

Number of existing Children, $\mathrm{n}=115$

\begin{tabular}{|c|c|c|}
\hline Number of children & Frequency & Percentage \\
\hline 0 & 40 & $34.78 \%$ \\
\hline 1 & 35 & $30.43 \%$ \\
\hline 2 & 25 & $21.74 \%$ \\
\hline 3 & 8 & $6.96 \%$ \\
\hline 4 \& Above & 7 & $6.09 \%$ \\
\hline Total & 115 & $100 \%$ \\
\hline
\end{tabular}

B. Sociocultural Aspects as Enabling Factors

1) Knowledge about ANC Visits

Healthcare knowledge enables women to become aware about their healthcare rights and expectations. Studies discovered that pregnant women with proper knowledge about ANC service have poor complication of diabetes, hypertensions, thyroid or any other complexities (Rosliza A, Muhamad J., 2011). From the study, its shows that (Figure 4), 6.96 percent women visits one time, 53.04 percent women visit 2 times, 24.35 percent women visits 3 times and lest 15.65 percent visits 4 or more times in private hospitals to take ANC services.

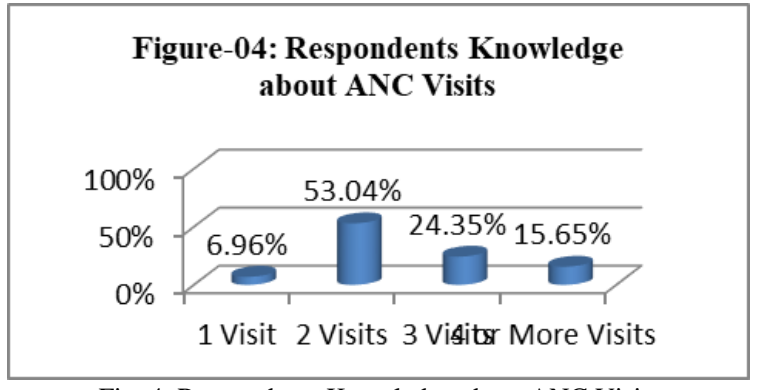

Fig. 4. Respondents Knowledge about ANC Visits

\section{2) Distance to Healthcare Center}

Studies revealed that health care utilization influenced by the distance of health care service centers. Long distance creates a barrier and demotivated women about the ANC services, especially the women who come from rural areas (Ali N.R. et al. 1999). Data shows that (Table 4) 13.04 percent women come at ANC center from 2-5 kilometers distance, 17.39 percent from 6-10 kilometers and lest 69.57 percent from 11 or above kilometers.

Table 4

Distance to Healthcare Center, $\mathrm{n}=115$

\begin{tabular}{|l|l|l|}
\hline Distance to health care center & Frequency & Percentage \\
\hline 2-5 Kilometers & 15 & $13.04 \%$ \\
\hline 6-10 Kilometers & 20 & $17.39 \%$ \\
\hline Above & 80 & $69.57 \%$ \\
\hline Total & 115 & $100 \%$ \\
\hline
\end{tabular}

\section{3) Types of Vehicle Used to Reach ANC Center}

Another important factor influencing ANC services of pregnant women is the types of vehicle used to reach ANC center. Most of the women feel fear to go an ANC center by any local vehicle but the government and respective authorities did not ensure such type of safety vehicle service for pregnant women. Data shows that (Figure 5), 40.21 percent women use bus to go an ANCE center, 35.14 percent use CNG, 14.22 percent use rickshaw or van and lest 10.43 percent go by foot walk.

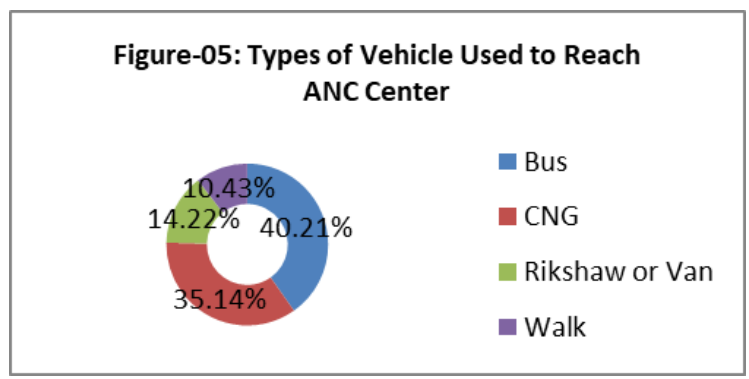

Fig. 5. Types of Vehicle Used to Reach ANC Center

\section{4) No. of ANC Visits in Last Pregnancy}

As a developing country Bangladesh also try to ensure a quality health care service. Government spread out maternal services door to door. Data found that (Figure 6), 18.26 percent women had one visit, 31.30 percent had two visits, 16.52 percent had three visits and lest 7.82 percent had four or more 
visits at ANC service center in their last pregnancy.

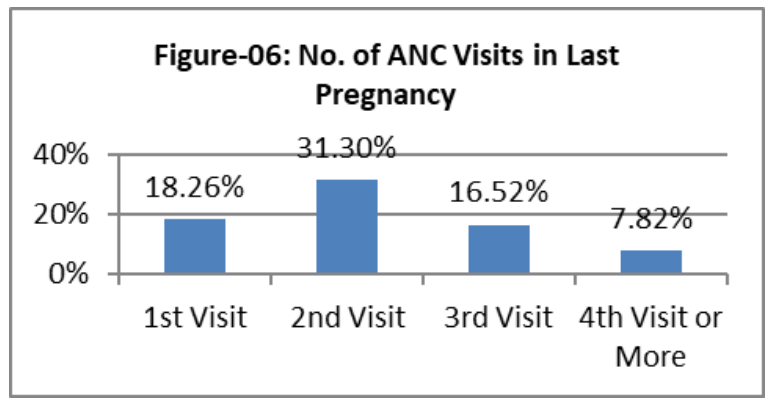

Fig. 6. No. of ANC Visits in Last Pregnancy

\section{5) Partners Attitude toward ANC Services}

Husband's positive attitude to his wife's ANC services is very much important for a safe birth. Researchers found that women having supportive husband utilized ANC services nearly three weeks than who had no assistance (Gross, K. 2012). Data shows that (Table 5), 60.87 percent husbands have positive attitude, 29.56 percent have negative attitude and lest 9.57 percent have neutral attitude toward ANC services.

Table 5

Husbands Attitude about ANC Services, $\mathrm{n}=115$

\begin{tabular}{|l|l|l|}
\hline Husband attitudes towards ANC services & Frequency & Percentage \\
\hline Positive & 70 & $60.87 \%$ \\
\hline Negative & 34 & $29.56 \%$ \\
\hline Neutral & 11 & $9.57 \%$ \\
\hline Total & 115 & $100 \%$ \\
\hline
\end{tabular}

\section{Obstetrical Aspects as Need Factors}

\section{1) Behavior of ANC Service Provider}

Behavior refers to the ways you conduct yourself toward others. The behaviors of ANC service provider (doctors, nurses, midwife) are very much important to encourage pregnant women that they take ANC service. This study data shows that (Table 6), 44.34 percent women say about good behavior, 34.79 percent have very good behavior, 20.87 percent have bad behavior of the ANCE service providers.

Table 6

Behavior of ANC Provider, $\mathrm{n}=115$

\begin{tabular}{|l|l|l|}
\hline Behavior of care providers & Frequency & Percentage \\
\hline Good & 51 & $44.34 \%$ \\
\hline Very good & 40 & $34.79 \%$ \\
\hline Bad & 24 & $20.87 \%$ \\
\hline Total & 115 & $100 \%$ \\
\hline
\end{tabular}

2) Waiting Time to take ANC Services

Table 7

Waiting Time to take ANC Services, $\mathrm{n}=115$

\begin{tabular}{|c|c|c|}
\hline Waiting time & Frequency & Percentage \\
\hline $10-20$ minutes & 16 & $13.91 \%$ \\
\hline 21-30 minutes & 29 & $25.22 \%$ \\
\hline Above 30 minutes & 70 & $60.87 \%$ \\
\hline Total & 115 & $100 \%$ \\
\hline
\end{tabular}

Another important ANC service factor that influence pregnant women in Bangladesh is waiting time to take ANC services. Data found that (Table 7), 13.91 percent women said that they waited nearly 10-20 minutes for getting ANC services,
25.22 percent waited nearly $21-30$ minutes and 60.87 percent waited above 30 minutes.

3) Availability of ANC Service Providers

Availability of skilled ANC service provider is the last and chief need ANC service factors for pregnant women especially in rural areas. Study data shows that (Table 8), 65.22 percent women consent about the obtainability of ANC service provider in pastoral regions. On the other hand, 75.65 percent pregnant women consent about the obtainability of ANC service provider in city zones.

Table 8

Availability of ANC Service providers, $\mathrm{n}=115$

\begin{tabular}{|c|c|c|c|}
\hline & & Frequency & Percentage \\
\hline \multirow[t]{2}{*}{ Rural Area } & Availability in rural area & 75 & $65.22 \%$ \\
\hline & Non- Availability & 40 & $34.78 \%$ \\
\hline \multicolumn{2}{|r|}{ Total } & 115 & $100 \%$ \\
\hline \multirow[t]{2}{*}{ Urban Area } & Availability in rural area & 87 & $75.65 \%$ \\
\hline & Non- Availability & 28 & $24.35 \%$ \\
\hline \multicolumn{2}{|r|}{ Total } & 115 & $100 \%$ \\
\hline
\end{tabular}

\section{Conclusion}

Finally, studies found that antennal care is required for all antenatal women come from both urban and rural areas. In this review study it found that the position of antenatal care visit is not at a satisfactory level. A large percentage of the pregnant women do not have any knowledge about antenatal care service and no access to WHO suggested minimum four ANC visits. The result of this study also found that the application rate of ANC services is very low at TMSS medical college and Rafatullah community hospital in Bogura district. The foremost aspects influencing the utilization of ANC are attendant's level of education, socio-economic status, supportive spouse or partner, lack of women's knowledge about ANC, distance of health care facilities, long waiting time and decision making power of women etc. This study also found some benefits of ANC service which should proclaim among the pregnant women, among the newly married couples Disseminating the benefits of ANC should be stressed so that the communities take active part in the utilization of antenatal care facilities. In areas where accessibility to antenatal care facilities is a problem, community should provide antenatal counseling at the door steps of women's.

\section{Recommendations}

The review study recommended that we need to develop mass community awareness about the benefits of antenatal service especially among the women who are making plan to take children, among pregnant women, among doctors, nurses, midwives and respective stakeholders who are related to such type of programs. To strengthen such type of programs we need to raise home visit and emphasis on the role of community leaders in empowering pregnant women to seek ANC services much early in order to reduce pregnancy associated complication. Doctors, nurses, midwife engagement in early ANC attendance through education and sensitization both in ANC matters and other related concerns. Awareness of mothers 
about the danger signs of pregnant should increase and the importance of ANC utilization in addressing the problem. Women's autonomy within the family should enhance that they gain ability to earn and control income and decide on their own health. The health officers should monitor the pregnant women about ANC visits and should be given a view on how many ANC visits receive from pregnant women. Finally, respective authorities should develop more strategies regarding reduction of maternal mortality and safe newborns.

\section{References}

[1] Adekanle, D.A, Isawumi, A.I. (2008). "Late Antenatal Care Booking And Its Predictors Among Pregnant Women In South Western Nigeria". Online J Health Allied Scs. 2008;7(1):4.

[2] Ali N, Sultana M, Sheikh N, et al. (2018). Predictors of Optimal Antenatal Care Service Utilization Among Adolescents and Adult Women in Bangladesh. Health Services Research and Managerial Epidemiology. January 2018.

[3] Ali SA, Dero AA, Ali SA, et al. Factors affecting the utilization of antenatal care among pregnant women: A literature review. J Preg Neonatal Med 2018;2(2):41-45.

[4] Andersen, Ronald (1995). "Revisiting the behavioral model and access to medical care: does it matter?". J. Health Soc Behav. 36 (1): 1-10.

[5] Basha W.G. (2019). "Factors Affecting the Utilization of a Minimum of Four Antenatal Care Services in Ethiopia". Hindawi journal of Obstetrics and Gynecology International Volume 2019, Article ID 5036783, 6 pages.

[6] Begum, N., Rahman, M, Nayan, S.K. et al. (2014). "Utilization of Antenatal care Services in a selected Rural area in Bangladesh". Northern International Medical College Journal, July 2014, Volume 6, Number 1.

[7] Bilenko, Natalya, Hammel R. et al. (2007). "Utilization of antenatal care services by a semi-nomadic Bedouin Arab population: evaluation of the impact of a local maternal and child health clinic." Maternal and Child Health Journal, Vol. 11, No. 5, 2007, pp. 425-30.

[8] Chowdhury S., Banu L. A. et al. (2011). "Achieving Millennium Development Goals 4 and 5 in Bangladesh". BJOG 2011; 118 (Suppl. 2):36-46.

[9] Efendi F, Chen CM, Kurniati A, et al. (2016). "Determinants of utilization of antenatal care services among adolescent girls and young women in Indonesia". J Women Health. 2016:1-16.
[10] Moller, A. B, Petzold, M., Chou, D., et al. (2017). "Early antenatal care visit: a systematic analysis of regional and global levels and trends of coverage from 1990 to 2013". The Lancet Global Health, Volume 5, Issue 10, Pages e977-e983.

[11] Nketiah-Amponsah E, Senadza B, Arthur E. (2013). "Determinants of utilization of antenatal care services in developing countries: recent evidence from Ghana”. African J Econ Manag Stud. 2013;4:58-73.

[12] Pervin, J., Moran, A., Rahman, M. et al. (2012). "Association of antenatal care with facility delivery and perinatal survival - a population-based study in Bangladesh". BMC Pregnancy Childbirth 12, 111.

[13] Say L et al. (2014), 'Global causes of maternal death: a WHO systematic analysis' Lancet Global Health.

[14] Shahjahan, M., Chowdhury, H.A., Akter, J. et al. (2012). "Factors associated with use of antenatal care services in a rural area of Bangladesh". South East Asia Journal of Public Health 2012;2(2):61-66.

[15] UNICEF, (2015). The State of the World's Children Report. New York, NY, USA: UNICEF; 2015. UNICEF data: monitoring the situation of children and women.

[16] UNICEF, (2021). Global database of antenatal care, based on MICS, DHS and other nationally representative household survey data. https://data.unicef.org/topic/maternal-health/antenatal-care.

[17] WHO, (2019). "Trends in maternal mortality: 2000 to 2017: estimates by WHO, UNICEF, UNFPA, World Bank Group and the United Nations Population Division". Geneva: World Health Organization; 2019.

[18] World Health Organization (WHO), (2020). Maternal and reproductive health research report, https://www.who.int/docs/default-source/countryprofiles/bangladesh.

[19] Yohannes, B., Tarekegn, M. et al. (2013). "Mothers" Utilization of Antenatal Care and their Satisfaction with Delivery Services in Selected Public Health Facilities of Wolaita Zone, Southern Ethiopia”. International Journal of Scientific \& Technology, Volume 2, Issue 2, February 2013.

[20] Zhao QZJH, Yang S, Pan J, et al. (2012). "The utilization of antenatal care among rural-to-urban migrant women in Shanghai: A hospital-based cross-sectional study". BMC Public Health. 2012;12.

[21] Rosliza A, Muhamad J, (2011). "Knowledge, attitude and practice on antenatal care among orang asli women in Jempol, Negeri Sembilan". Malaysian J Public Health Med. 2011;11:13-21.

[22] Ali N.R., Luby S., Hossein Rahbar M., (1999). Does use of a government service depend on distance from the health facility? Health Policy and Planning. 1999;14:191.

[23] Gross K, Alba S, Glass TR, et al. (2012). Timing of antenatal care for adolescent and adult pregnant women in south-eastern Tanzania. BMC Preg Childbirth. 2012;12:1. 